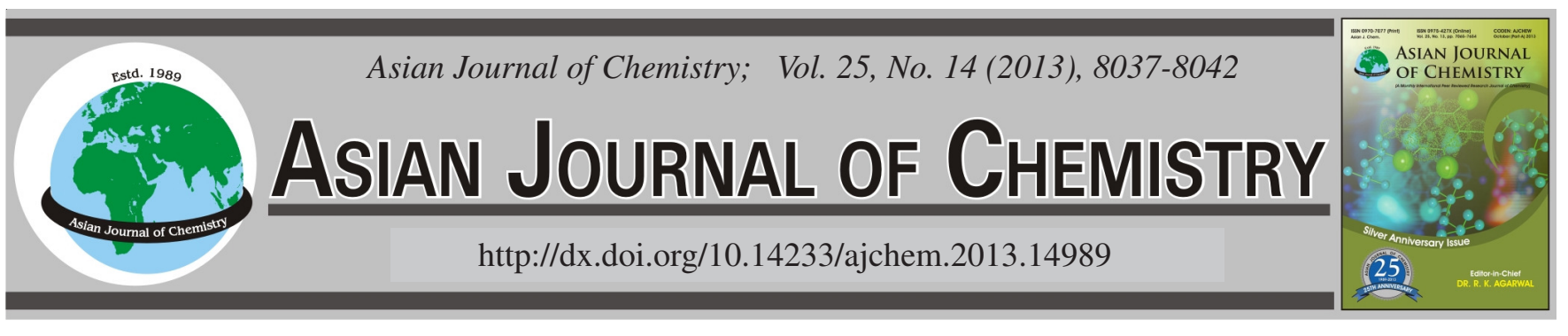

\title{
Thermodynamic Interactions Due to Transfer of Amino Acids, Glycine and DL-Alanine from Water to Aqueous Mixture of Cationophilic Dipolar Aprotic $N, N$-Dimethyl Formamide
}

\author{
S. RoY ${ }^{1}$, K. MAHALI ${ }^{2}$ and B.K. Dolui ${ }^{3, *}$
}

${ }^{1}$ Department of Chemistry, Shibpur Dinobundhoo Institution (College), Howrah-711 102, India

${ }^{2}$ Department of Chemistry, University of Kalyani, Nadia-741 235, India

${ }^{3}$ Department of Chemistry, Visva-Bharati University, Santiniketan-731 235, India

*Corresponding author: E-mail: bijoy_dolui@yahoo.co.in

(Received: 18 December 2012;

Accepted: 1 August 2013)

AJC-13868

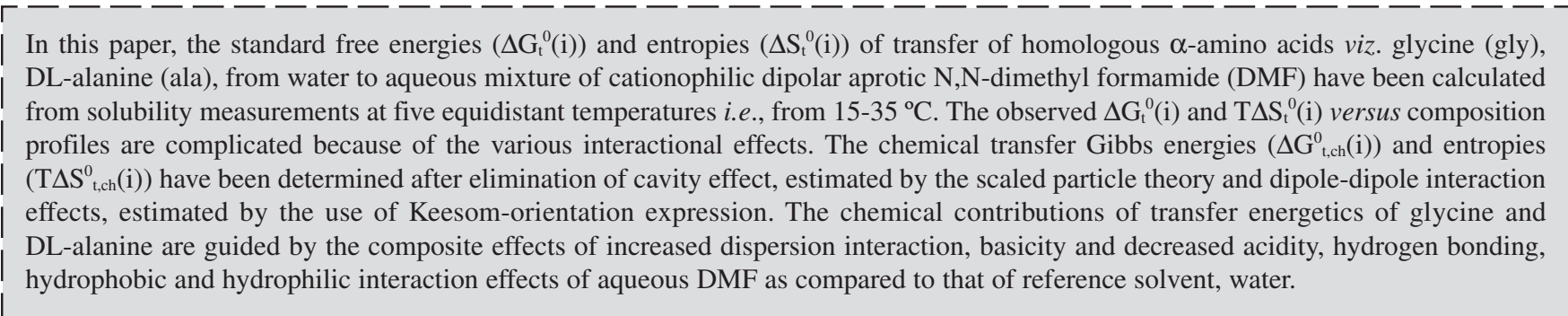

Key Words: Transfer energetics, $\alpha$-Amino acids, Aqueous solvent system, Dispersion interaction.

\section{INTRODUCTION}

Amino acids play an important role in our body. They play central roles both as building blocks of proteins and as intermediates in metabolism. The different chemical properties of the amino acids determine the biological activity of the protein. Proteins not only catalyze all (or most) of the reactions in living cells, they also control virtually all cellular process. The native state of a protein is determined by the nature and sequence of its constituent's amino acids as well as by the solvent environment.

From these points of view many researchers had drawn their attention ${ }^{1-5}$ to determine the various thermodynamic properties of amino acids in aqua-organic mixed solvent system.

The aims of such studies were to gain the various aspects of protein folding and unfolding process and protein hydration $^{6-9}$. In this regard Tanford ${ }^{10}$, and Lyyah and Shehabuddin ${ }^{11}$ reported free energies of some amino acids from water to urea from solubility measurements. Transfer free energies and entropies data of some amino acids, dipeptides, tripeptides and other biomolecules in aqueous ethylene glycol $^{12,13}$, glycerol $^{14,15}$ and $\mathrm{N}, \mathrm{N}$-dimethyl formamide ${ }^{16}$ are also available.

All these experiments tried to give an explanation about the relative stabilization of these amino acids and other biomolecules in aqua-organic media with respect to water and the complex solute-solvent and solvent-solvent interactions therein.

Here we have used two simple $\alpha$-amino amino acids like glycine and DL-alanine. The $\alpha$-carbon of DL-alanine is bound with a $-\mathrm{CH}_{3}$ group whereas in glycine no such group is present. So the aqua-organic chemistry regarding thermodynamic solvation of these two $\alpha$-amino amino acids may be different in various aspects. In our experiments here we have used amide like solvent N,N-dimethyl formamide in particular. This will be very much useful for better understanding of the biological processes because the environment in which the different biological activities occur may be much more 'amide like' than 'water like' ${ }^{17}$.

In the present article we are reporting the transfer free energies $\left[\Delta \mathrm{G}_{\mathrm{t}}^{0}(\mathrm{i})\right]$ and entropies $\left[\Delta \mathrm{S}_{\mathrm{t}}^{0}(\mathrm{i})\right]$ of these $\alpha$-amino a cids, namely glycine(gly), DL-alanine (ala), from water to aqueous mixture of dipolar aprotic N,N-dimethyl formamide at $25{ }^{\circ} \mathrm{C}$, as determined from solubility measurements using 'formol titrimetry' at five equidistant temperatures ranging from 15 to $35^{\circ} \mathrm{C}$.

After eliminating effects due to cavity formation and dipole-dipole interactions and neglecting dipole-induced dipole interactions the results have been discussed in terms of 
dispersion interaction, acidity-basicity, hydrophilic and hydrophobic hydration and in the case of transfer entropies in terms of relative structuredness as well.

\section{EXPERIMENTAL}

Amino acids like glycine (E Merck) and DL-alanine ( E-Merck) are used after drying as described earlier ${ }^{12,13}$. N,NDimethyl formamide (LR, BDH) and water are purified by the usual method ${ }^{18}$. Aqueous mixtures of co-solvent $\left(\mathrm{H}_{2} \mathrm{O}+\right.$ DMF) that have been used were 20, 40, 60, 80 and 100 wt $\%$. The solubility of these amino acids was measured by formol titrimetry method. These measurements were taken at 15, 20, 25,30 and $35^{\circ} \mathrm{C}$ temperatures. The low-cum-high temperature thermostat used for all measurements was capable of registering temperatures having an accuracy of $\pm 0.1^{\circ} \mathrm{C}$. Four sets of measurements were made for all the solutes by equilibrating the solutions from both above and below the required temperatures and at least three sets of measurements were made for all the solvents and the solubilities were found to agree to within $\pm 1.0-1.5 \%$.

\section{RESULTS AND DISCUSSION}

The solubilities (m) of the $\alpha$-amino acids, glycine and DL-alanine on molal scale are listed in the Table-1. In the previous studies by Bates and coworkers on Tris ${ }^{19}$ and by Kundu and coworkers ${ }^{19,20}$ on non-electrolyte like pNA, HBz and amino acids ${ }^{21}$, glycine (G), diglycine (DG) and triglycine
(TG), the Gibbs energies of solutions $\left(\Delta \mathrm{G}_{\mathrm{S}}{ }^{0}\right)$ on molal scale were calculated for each solvent using eqn. 1 .

$$
\Delta \mathrm{G}_{\mathrm{s}}^{0}(\mathrm{i})=-\mathrm{RT} \ln \mathrm{C} \gamma=-\mathrm{RT} \ln \mathrm{C}=-\mathrm{RT} \ln \mathrm{m}
$$

where $\gamma$ is the molar activity coefficient of the solutes but taken tentatively to be unity in each solvent. Since $\alpha$-amino acids, glycine and DL-alanine likely to be mostly in zwitterionic forms as in non-aqueous solvent mixtures ${ }^{22,23}$. The involved activity coefficient factor -RT $\ln \mathrm{C} \gamma$ in arising from interactions of dipolar solutes (here $\alpha$-amino acids) with large dipole moments may not be so small. But as there is neither the required experimental data nor any appropriate theoretical correlations for computing the same, these have been tacitly taken to be negligibly small, as is usually done for non-electrolytes $^{24}$. This is because the effective contribution of activity coefficient factor -RT $\ln \gamma_{\mathrm{s}} / \gamma_{\mathrm{R}}$ in the transfer free energetics; $\Delta \mathrm{G}_{\mathrm{t}}^{0}(\mathrm{i})=\Delta \mathrm{G}_{\mathrm{s}}^{0}(\mathrm{i})-\Delta \mathrm{G}_{\mathrm{R}}^{0}(\mathrm{i})$ in particular which is our main concern likely to be hardly significant.

The free energies, at different temperatures are fitted by the method of least squares to an equation of the form[2],

$$
\Delta \mathrm{G}_{\mathrm{s}}^{0}=\mathrm{a}+\mathrm{bT}+\mathrm{cT} \ln \mathrm{T}
$$

where $\mathrm{T}$ is the temperature in Kelvin scale. The values of the coefficients a, b, c are presented in Table-2. These are found to reproduce the experimental data within $\pm 0.04 \mathrm{~kJ} \mathrm{~mol}^{-1}$. Transfer Gibbs energies and entropies of the amino acids from water to N,N-dimethyl formamide mixtures were calculated at $25^{\circ} \mathrm{C}$ on mole fraction scale by using the following eqns. 3 and 4:

\begin{tabular}{|c|c|c|c|c|c|c|c|c|c|c|}
\hline \multirow{2}{*}{ Wt $\%$ solvent } & \multicolumn{5}{|c|}{ Glycine } & \multicolumn{5}{|c|}{ Dl-alanine } \\
\hline & $15^{\circ} \mathrm{C}$ & $20^{\circ} \mathrm{C}$ & $25^{\circ} \mathrm{C}$ & $30^{\circ} \mathrm{C}$ & $35^{\circ} \mathrm{C}$ & $15^{\circ} \mathrm{C}$ & $20^{\circ} \mathrm{C}$ & $25^{\circ} \mathrm{C}$ & $30^{\circ} \mathrm{C}$ & 35 \\
\hline Water & 2.720 & 3.060 & 3.340 & 3.720 & 4.060 & 1.634 & 1.720 & 1.800 & 2.300 & 2.400 \\
\hline- & $(2.690)^{\mathrm{a}}$ & - & $(3.330)^{\mathrm{a}}$ & - & $(4.040)^{\mathrm{a}}$ & $(1.650)^{\mathrm{a}}$ & - & (1.850) & - & $(2.390)^{\mathrm{a}}$ \\
\hline $20 \% \mathrm{DMF}$ & 0.103 & 0.110 & 0.118 & 0.120 & 0.128 & 0.111 & 0.124 & 0.138 & 0.147 & 0.157 \\
\hline $40 \% \mathrm{DMF}$ & 0.086 & 0.098 & 0.109 & 0.112 & 0.114 & 0.085 & 0.106 & 0.126 & 0.132 & 0.138 \\
\hline $60 \%$ DMF & 0.069 & 0.081 & 0.091 & 0.095 & 0.099 & 0.068 & 0.079 & 0.089 & 0.094 & 0.098 \\
\hline $80 \%$ DMF & 0.058 & 0.066 & 0.074 & 0.077 & 0.079 & 0.058 & 0.065 & 0.072 & 0.077 & 0.080 \\
\hline $100 \% \mathrm{DMF}$ & 0.038 & 0.042 & 0.045 & 0.049 & 0.053 & 0.041 & $0.044^{b}$ & 0.047 & $0.052^{\mathrm{b}}$ & 0.056 \\
\hline- & $(0.038)^{\mathrm{b}}$ & - & $(0.046)^{\mathrm{b}}$ & - & $(0.052)^{\mathrm{b}}$ & - & $(0.041)^{\mathrm{b}}$ & $(0.048)^{\mathrm{b}}$ & - & $(0.055)^{b}$ \\
\hline
\end{tabular}

SOLUBILITIES (m) OF GLYCINE, DL-ALANINE IN AQUEOUS MIXTURES OF DMF AT DIFFERENT TEMPERATURES $\left({ }^{\circ} \mathrm{C}\right)$

TABLE-2

COEFFICIENTS a, b AND c OF GLYCINE, DL-ALANINE AND GIBBS ENERGIES $\Delta \mathrm{G}_{\mathrm{t}}^{0}$ AND ENTROPIES T $\Delta \mathrm{S}_{\mathrm{t}}^{0} \mathrm{OF}_{\mathrm{TRANSFER}}$

\begin{tabular}{|c|c|c|c|c|c|}
\hline Solvents & $\mathrm{a}\left(\mathrm{kJmol}^{-1}\right)$ & $\mathrm{b}\left(\mathrm{kJ} \mathrm{mol}^{-1} \mathrm{~K}^{-1}\right)$ & $\mathrm{c}\left(\mathrm{kJ} \mathrm{mol}^{-1} \mathrm{~K}^{-1}\right)$ & $\Delta \mathrm{G}_{\mathrm{t}}^{0} \quad\left(\mathrm{~kJ} \mathrm{~mol}^{-1}\right)$ & $\mathrm{T} \Delta \mathrm{S}_{\mathrm{t}}^{0}\left(\mathrm{~kJ} \mathrm{~mol}^{-1}\right)$ \\
\hline \multicolumn{6}{|c|}{ Glycine } \\
\hline Water & 36.54 & -0.5500 & 0.07326 & 0 & 0 \\
\hline $40 \% \mathrm{DMF}$ & 373.32 & -8.1742 & 1.21816 & 7.264 & -11.836 \\
\hline $60 \% \mathrm{DMF}$ & 378.06 & -8.2274 & 1.22497 & 7.469 & -9.332 \\
\hline $80 \% \mathrm{DMF}$ & 342.94 & -7.4672 & 1.11253 & 7.197 & -10.655 \\
\hline $100 \% \mathrm{DMF}$ & 124.76 & -2.5575 & 0.37993 & 7.164 & -10.378 \\
\hline \multicolumn{6}{|c|}{ dl-Alanine } \\
\hline Water & -239.99 & 5.6871 & -0.85782 & 0 & 0 \\
\hline $20 \% \mathrm{DMF}$ & 155.27 & -3.2290 & 0.47823 & 6.119 & -9.203 \\
\hline $40 \% \mathrm{DMF}$ & 584.07 & -12.7728 & 1.90100 & 5.508 & -3.991 \\
\hline $60 \% \mathrm{DMF}$ & 313.77 & -6.7700 & 1.00707 & 6.148 & -8.405 \\
\hline $80 \% \mathrm{DMF}$ & 159.82 & -3.3262 & 0.49357 & 5.865 & -8.972 \\
\hline $100 \% \mathrm{DMF}$ & 30.18 & -0.4409 & 0.06406 & 5.668 & -10.356 \\
\hline
\end{tabular}
OF THE ACIDS (ON MOLE FRACTION SCALE) IN kJ mol ${ }^{-1}$ FROM WATER TO AQUEOUS-DMF MIXTURE AT $25^{\circ} \mathrm{C}$ 


$$
\Delta \mathrm{G}_{\mathrm{t}}^{0}(\mathrm{i})={ }_{\mathrm{s}} \Delta \mathrm{G}_{\mathrm{s}}^{0}-{ }_{\mathrm{R}} \Delta \mathrm{G}_{\mathrm{s}}^{0}(\mathrm{i})
$$

i.e. $\quad \Delta \mathrm{G}_{\mathrm{t}}^{0}(\mathrm{i})=\left(\mathrm{a}_{\mathrm{s}}-\mathrm{a}_{\mathrm{R}}\right)+\left(\mathrm{b}_{\mathrm{s}}-\mathrm{b}_{\mathrm{R}}\right) \mathrm{T}+\left(\mathrm{c}_{\mathrm{s}}-\mathrm{c}_{\mathrm{R}}\right) \mathrm{T} \ln \mathrm{T}$

$$
-\mathrm{RT} \ln \left(\frac{\mathrm{M}_{\mathrm{s}}}{\mathrm{M}_{\mathrm{R}}}\right)
$$

and $\Delta \mathrm{S}_{\mathrm{t}}^{0}(\mathrm{i})=\left(\mathrm{b}_{\mathrm{R}}-\mathrm{b}_{\mathrm{s}}\right)+\left(\mathrm{c}_{\mathrm{R}}-\mathrm{c}_{\mathrm{S}}\right)(1+\ln \mathrm{T})+\mathrm{R} \ln \left(\frac{\mathrm{M}_{\mathrm{s}}}{\mathrm{M}_{\mathrm{R}}}\right)$

here the subscript ' $\mathrm{s}$ ' and ' $\mathrm{R}$ ' refer to the co- solvent $\left(\mathrm{H}_{2} \mathrm{O}+\right.$ DMF) mixtures and reference solvent $\left(\mathrm{H}_{2} \mathrm{O}\right)$, respectively and $\mathrm{M}_{\mathrm{R}}$ and $\mathrm{M}_{\mathrm{s}}$ are the molar mass of the pure and mixed solvent, respectively. $\Delta \mathrm{G}_{\mathrm{t}}{ }^{0}(\mathrm{i})$ and $\Delta \mathrm{S}_{\mathrm{t}}{ }^{0}(\mathrm{i})$ values of amino acids, glycine and DL-alanine thus obtained and presented in the Table-2. The involved uncertainties in $\Delta \mathrm{G}_{\mathrm{t}}^{0}(\mathrm{i})$ and $\Delta \mathrm{S}_{\mathrm{t}}{ }^{0}(\mathrm{i})$ are $c a . \pm 0.05$ $\mathrm{kJ} \mathrm{mol}^{-1}$ and $2 \mathrm{JK}^{-1} \mathrm{~mol}^{-1}$, respectively.

Now $\Delta \mathrm{P}_{\mathrm{t}}^{0}$ (where $\mathrm{P}=\mathrm{G}$ or $\mathrm{S}$ ) may be ascribed as the sum of the following terms (assuming dipole induced dipole term to be negligibly small).

$$
\text { i.e. } \quad \Delta \mathrm{P}_{\mathrm{t}}^{0}(\mathrm{i})=\Delta \mathrm{P}_{\mathrm{t}, \mathrm{cav}}^{0}(\mathrm{i})+\Delta \mathrm{P}_{\mathrm{t}, \mathrm{d}-\mathrm{d}}^{0}(\mathrm{i})+\Delta \mathrm{P}_{\mathrm{t}, \mathrm{ch}}^{0}(\mathrm{i})
$$

here, $\Delta \mathrm{P}_{t, \text { cav }}^{0}$ indicates the transfer energy contribution of the cavity effect which is involved due to creation of cavities for the species in $\mathrm{H}_{2} \mathrm{O}$ and $\mathrm{H}_{2} \mathrm{O}+$ DMF mixed solvent system and $\Delta \mathrm{P}_{\mathrm{t}, \mathrm{d}-\mathrm{d}}^{0}(\mathrm{i})$ stands for the dipole-dipole interaction effect involving interaction between dipolar-zwitter-ionic amino acids and the solvent molecules. On the other hand, $\Delta \mathrm{P}_{\mathrm{t}, \mathrm{ch}}^{0}(\mathrm{i})$ includes all other effects such as those arising from acid-base or shortrange dispersion interaction, hydrophilic or hydrophobic hydration and structural effects etc. Here $\Delta \mathrm{P}_{t, \text { cav }}^{0}(\mathrm{i})$ values were computed by using scaled particle theory $(\mathrm{SPT})^{13,25,18}$, assuming the solutes and solvent molecules as equivalent to hard-sphere models as dictated by their respective diameter (Table-3).

$$
\begin{aligned}
& \Delta \mathrm{G}_{\mathrm{t}, \mathrm{d}-\mathrm{d}}^{0}(\mathrm{i})=\left({ }_{\mathrm{s}} \Delta \mathrm{G}_{\mathrm{d}-\mathrm{d}}^{0}(\mathrm{i})-_{\mathrm{R}} \Delta \mathrm{G}_{\mathrm{d}-\mathrm{d}}^{0}(\mathrm{i})\right) \text { and } \Delta \mathrm{S}_{\mathrm{t}, \mathrm{d}-\mathrm{d}}^{0}(\mathrm{i})= \\
& \left.{ }_{\mathrm{s}} \Delta \mathrm{S}_{\mathrm{d}-\mathrm{d}}^{0}(\mathrm{i})-_{\mathrm{R}} \Delta \mathrm{S}_{\mathrm{d}-\mathrm{d}}^{0}(\mathrm{i})\right) \text { are calculated by means of the }
\end{aligned}
$$

Keesom-orientation expression ${ }^{27}$ for ${ }_{\mathrm{s}} \Delta \mathrm{G}_{\mathrm{d}-\mathrm{d}}^{0}(\mathrm{i})$ in a solvent $\mathrm{S}$, as given below

$$
{ }_{\mathrm{s}} \Delta \mathrm{G}_{\mathrm{d}-\mathrm{d}}^{0}(\mathrm{i})=-\left(\frac{8 \Pi}{9}\right) \mathrm{N}^{2} \mu_{\mathrm{s}}^{2} \mu_{\mathrm{x}}^{2} \sigma_{\mathrm{sx}}^{-3}(\mathrm{kT})^{-1} \mathrm{v}_{\mathrm{s}}^{-1}=\frac{\mathrm{A}}{\mathrm{TV}_{\mathrm{s}}}
$$

where $\mathrm{A}=-\left(\frac{8 \Pi}{9}\right) \mathrm{N}^{2} \mu_{\mathrm{s}}^{2} \mu_{\mathrm{x}}^{2} \sigma_{\mathrm{sx}}^{-3}(\mathrm{k})^{-1}$ and $\mathrm{V}_{\mathrm{s}}=\frac{\mathrm{M}_{\mathrm{s}}}{\mathrm{d}_{\mathrm{s}}}$ and that of $\Delta \mathrm{S}_{\mathrm{d}-\mathrm{d}}^{0}(\mathrm{i})$ as follow-

$$
{ }_{\mathrm{s}} \Delta \mathrm{S}_{\mathrm{d}-\mathrm{d}}^{0}(\mathrm{i})=\left\{\frac{\delta_{\mathrm{s}} \Delta \mathrm{G}_{\mathrm{d}-\mathrm{d}}^{0}(\mathrm{i})}{\delta \mathrm{T}}\right\}_{\mathrm{p}}
$$

i.e., $\mathrm{T}_{\mathrm{s}} \Delta \mathrm{S}_{\mathrm{d}-\mathrm{d}}^{0}(\mathrm{i})={ }_{\mathrm{s}} \Delta \mathrm{G}_{\mathrm{d}-\mathrm{d}}^{0}(\mathrm{i})[1+\mathrm{T} \alpha]$, where $\mathrm{N}$ stands for Avogadro's number, $\mu_{\mathrm{s}}, \mu_{\mathrm{x}}$ are the dipole moment of solvents and amino acid molecules, respectively (Table-3).

$\sigma_{\mathrm{sx}}$ is the distance at which the attractive and repulsive interactions between the solvent and solute molecules are equal and is generally equal to $1 / 2\left(\sigma_{\mathrm{s}}+\sigma_{\mathrm{x}}\right)$, where $\sigma_{\mathrm{s}}$ and $\sigma_{\mathrm{x}}$ are the hard sphere diameter of co-solvent and solute molecules, respectively (Table-3) and $\alpha$ is the isothermal expansibility of the solvent and given by $\left(\frac{\delta \ln \mathrm{V}_{\mathrm{s}}}{\delta \mathrm{T}}\right)_{\mathrm{P}}=-\left(\frac{\delta \ln \mathrm{d}_{\mathrm{s}}}{\delta \mathrm{T}}\right)$. Following Marcus ${ }^{26}$ and Kim et al. ${ }^{27}$ in order to get this $\Delta \mathrm{P}_{\mathrm{t}, \mathrm{d}-\mathrm{d}}^{0}(\mathrm{i})$ term on

\begin{tabular}{|c|c|c|c|c|c|c|c|c|c|}
\hline \multicolumn{10}{|c|}{$\begin{array}{l}\Delta \mathrm{H}_{\mathrm{t}, \mathrm{cav}}^{0}(\mathrm{i}) \text { AND ENTROPIES OF TRANSFER T } \Delta \mathrm{S}_{\mathrm{t}}^{0}(\mathrm{i}), \mathrm{T} \Delta \mathrm{S}_{\mathrm{t}, \mathrm{cav}}^{0}(\mathrm{i}), \mathrm{T} \Delta \mathrm{S}_{\mathrm{t}, \mathrm{dd}}^{0}(\mathrm{i}) \text { AND } \mathrm{T} \Delta \mathrm{S}_{\mathrm{t}, \mathrm{ch}}^{0}(\mathrm{i}) \text { OF GLYCINE} \\
\text { DL-ALANINE, FROM WATER TO AQUEOUS-DMF AT } 25^{\circ} \mathrm{C}\left(\mathrm{ON} \text { MOLE FRACTION SCALE IN kJ mol }{ }^{-1}\right.\end{array}$} \\
\hline Solvents & $\Delta \mathrm{G}_{\mathrm{t}}^{0}(\mathrm{i})$ & $\Delta \mathrm{G}_{\mathrm{t}, \mathrm{cav}}^{0}(\mathrm{i})$ & $\Delta \mathrm{G}_{\mathrm{t}, \mathrm{dd}}^{0}(\mathrm{i})$ & $\Delta \mathrm{G}_{\mathrm{t}, \mathrm{ch}}^{0}(\mathrm{i})$ & $\mathrm{T} \Delta \mathrm{S}_{\mathrm{t}}^{0}(\mathrm{i})$ & $\Delta \mathrm{H}_{\mathrm{t}, \mathrm{cav}}^{0}(\mathrm{i})$ & $\mathrm{T} \Delta \mathrm{S}_{\mathrm{t}, \mathrm{cav}}^{0}(\mathrm{i})$ & $\mathrm{T} \Delta \mathrm{S}_{\mathrm{t}, \mathrm{dd}}^{0}(\mathrm{i})$ & $\mathrm{T} \Delta \mathrm{S}_{\mathrm{t}, \mathrm{ch}}^{0}(\mathrm{i})$ \\
\hline \multicolumn{10}{|c|}{ Glycine } \\
\hline Water & 0 & 0 & 0 & 0 & 0 & 0 & 0 & 0 & 0 \\
\hline $20 \% \mathrm{DMF}$ & 7.921 & -1.440 & 0.734 & 8.627 & -14.948 & -0.04 & 1.400 & 0.692 & -17.04 \\
\hline $40 \% \mathrm{DMF}$ & 7.264 & -3.980 & 5.190 & 6.054 & -11.836 & -0.115 & 3.865 & 5.190 & -20.862 \\
\hline $60 \% \mathrm{DMF}$ & 7.469 & -4.540 & 7.840 & 4.169 & -9.332 & -0.062 & 4.478 & 7.130 & -20.940 \\
\hline $80 \% \mathrm{DMF}$ & 7.197 & -6.370 & 15.700 & -2.133 & -10.655 & 0.028 & 6.398 & 13.900 & -30.953 \\
\hline $100 \% \mathrm{DMF}$ & 7.164 & -8.110 & 21.100 & -5.826 & -10.378 & 1.050 & 9.160 & 15.600 & -35.138 \\
\hline \multicolumn{10}{|c|}{ Alanine } \\
\hline Water & 0 & 0 & 0 & 0 & 0 & 0 & 0 & 0 & 0 \\
\hline $20 \% \mathrm{DMF}$ & 6.119 & -1.54 & 0.580 & 7.079 & -9.203 & -0.045 & 1.495 & 0.540 & -11.238 \\
\hline $40 \% \mathrm{DMF}$ & 5.508 & -4.20 & 4.320 & 5.388 & -3.991 & -0.128 & 4.072 & 4.300 & -12.364 \\
\hline $60 \% \mathrm{DMF}$ & 6.148 & -4.78 & 5.910 & 5.018 & -8.405 & 0.071 & 4.851 & 5.200 & -18.456 \\
\hline $80 \% \mathrm{DMF}$ & 5.865 & -6.64 & 10.300 & 2.205 & -8.972 & 0.026 & 6.666 & 8.190 & -23.828 \\
\hline $100 \% \mathrm{DMF}$ & 5.668 & -8.30 & 12.500 & 1.468 & -10.356 & 1.020 & 9.320 & $6.040^{\circ}$ & -25.716 \\
\hline
\end{tabular}
mole fraction scale the quantity was again multiplied by the term $\mathrm{Xs}_{1}$ and

$$
X_{s 1}=X_{s} \frac{\left(\frac{\mu_{s}}{\sigma_{s}^{3}}\right)}{\left(\frac{\mu_{R}}{\sigma_{R}^{3}}\right)}
$$

This is the real mole fraction contribution due to dipoledipole interaction ${ }^{26}$. Subtraction of $\Delta \mathrm{P}_{\mathrm{t}, \mathrm{cav}}^{0}(\mathrm{i})$ and $\Delta \mathrm{P}_{\mathrm{t}, \mathrm{d}-\mathrm{d}}^{0}(\mathrm{i})$

The required diameter and other solvent parameters of DMF and water are taken from ref. ${ }^{26}$. The required diameter of glycine and alanine are 5.64 and $6.16 \AA$, as given in ref. ${ }^{23,29}$. Dipole moment values of $\alpha$-amino acids are 15.7D for glycine, 15.9D for alanine. 
from the total we can get $\Delta \mathrm{P}_{\mathrm{t}, \mathrm{ch}}^{0}$ (i) of amino acids. The values of, $\Delta \mathrm{P}_{\mathrm{t}, \text { cav }}^{0}(\mathrm{i}), \Delta \mathrm{P}_{\mathrm{t}, \mathrm{d}-\mathrm{d}}^{0}(\mathrm{i})$ and $\Delta \mathrm{P}_{\mathrm{t}, \mathrm{ch}}^{0}(\mathrm{i})$ are presented in Table-3.

Interactions involved between amino acids and solvent molecules: Fig. 1 shows the variation of $\Delta \mathrm{G}_{\mathrm{t}}{ }^{0}(\mathrm{i})$ with mol \% of DMF in aqueous DMF co-solvent system. The $\Delta \mathrm{G}_{\mathrm{t}}{ }^{0}(\mathrm{i})$ values indicate that the amino acids (glycine, DL-alanine) are almost destabilized in N,N-dimethyl formamide-water mixtures. These amino acids are destabilized more regularly up to 100 mol \% DMF. $\Delta \mathrm{G}_{\mathrm{t}}^{0}(\mathrm{i})$ is composed of, $\Delta \mathrm{G}_{\mathrm{t}, \mathrm{cav}}^{0}(\mathrm{i}), \Delta \mathrm{G}_{\mathrm{t}, \mathrm{dd}}^{0}(\mathrm{i})$ and $\Delta \mathrm{G}_{\mathrm{t}, \mathrm{ch}}^{0}(\mathrm{i})$ or others. So their collective contribution $\Delta \mathrm{G}_{\mathrm{t}}{ }^{0}(\mathrm{i})$ show such little complex nature of variation with mole $\%$ of N,Ndimethyl formamide.

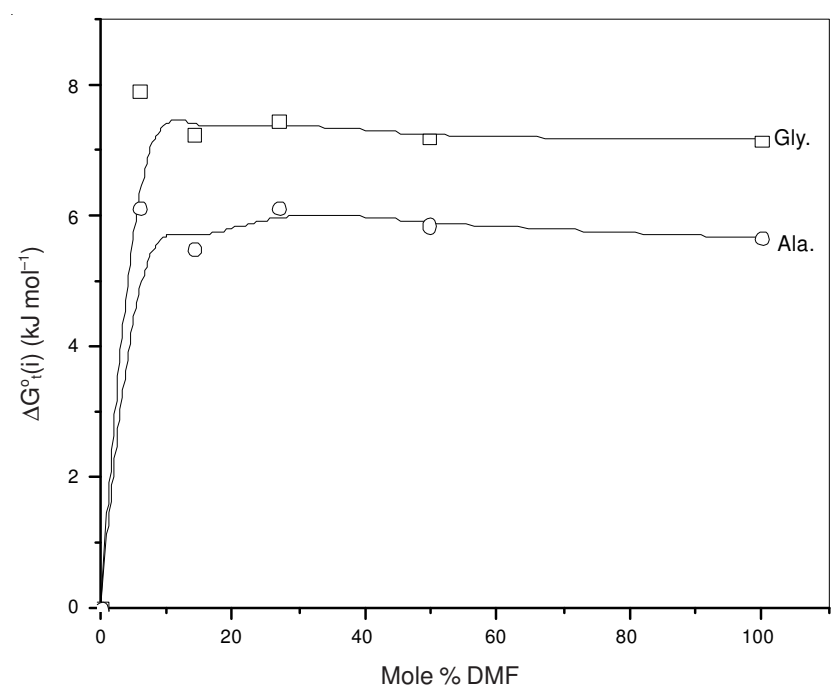

Fig. 1. Variation of $\Delta \mathrm{G}_{\mathrm{t}}^{0}(\mathrm{i})$ of glycine, DL-alanine with mole \% DMF aqueous mixture of DMF at $298.15 \mathrm{~K}$

Fig. 2 represents the variation of $\Delta \mathrm{G}_{\mathrm{t}, \mathrm{ch}}^{0}(\mathrm{i})$ with mole $\%$ $\mathrm{N}, \mathrm{N}$-dimethyl formamide in aqueous mixture. $\Delta \mathrm{G}_{\mathrm{t}, \mathrm{ch}}^{0}(\mathrm{i})$ can be obtained after eliminating $\Delta \mathrm{G}_{\mathrm{t}, \mathrm{cav}}^{0}(\mathrm{i})$ and $\Delta \mathrm{G}_{\mathrm{t}, \mathrm{d}-\mathrm{d}}^{0}(\mathrm{i})$ from the total.

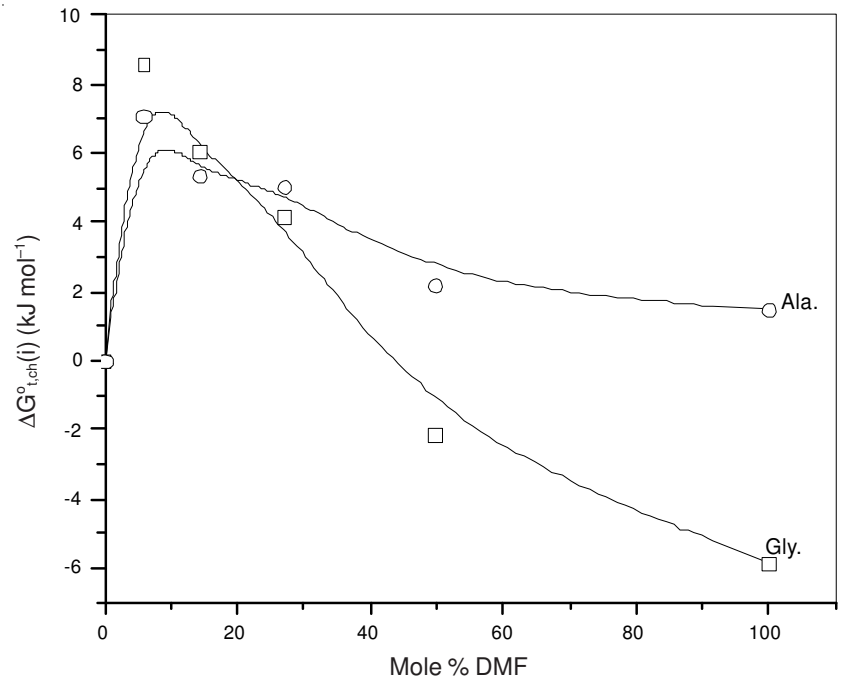

Fig. 2. Variation of $\Delta \mathrm{G}_{\mathrm{t}, \mathrm{ch}}^{0}(\mathrm{i})$ of glycine, DL-alanine with mole $\%$ DMF in aqueous mixture of DMF at $298.15 \mathrm{~K}$
The size of N,N-dimethyl formamide $(0.498 \AA)^{27}$ is greater than water $(0.274 \AA)^{27}$. Thus free energy change due to cavity formation is also more negative in $\mathrm{N}, \mathrm{N}$-dimethyl formamide relative to water. $\Delta \mathrm{G}_{\mathrm{t}, \text { cav }}^{0}(\mathrm{i})$ is more negative for DL-alanine having larger hard-sphere diameter (Table-3). On the other hand the dipole moment of N,N-dimethyl formamide (3.82 $\mathrm{D})^{30}$ is also greater than water $(1.85 \mathrm{D})^{26}$. Therefore, $\Delta \mathrm{G}_{\mathrm{t}, \mathrm{d}-\mathrm{d}}^{0}(\mathrm{i})$ values are more negative in higher concentration of $\mathrm{N}, \mathrm{N}-$ dimethyl formamide in this aqueous N,N-dimethyl formamide mixed solvent system. The order of $\Delta \mathrm{G}_{\mathrm{t}, \mathrm{d}-\mathrm{d}}^{0}(\mathrm{i})$ value is Gly. $>$ DL-Ala. As $\Delta \mathrm{G}_{\mathrm{t}, \mathrm{d}-\mathrm{d}}^{0}(\mathrm{i})$ values are guided by dipole moment and hard-sphere diameter of both solutes (here amino acid) as well as solvent, the above order is well supported from Table-3.

$\Delta \mathrm{G}_{\mathrm{t}, \mathrm{ch}}^{0}(\mathrm{i})$ values of these amino acids represent the free energy change in the water and N,N-dimethyl formamide mixed solvent system due to different short range chemical interactions i.e., acid-base, dispersion, hard-soft, H-bonding, hydrophilic and hydrophobic interactions etc. As the proportion of N,N-dimethyl formamide in the mixed solvent system will be gradually increased the solvent character may undergoes a gradual but material change in respect to the above types of chemical interactions. This compositive profile shows upward trends at lower concentration of N,N-dimethyl formamide and reaches a maximum value at ca. 8-10 mol \% of DMF concentration and then decreases. This indicates the destabilization of $\alpha$-amino acids. This occurs due to the breakdown of extensive hydrogen bond between protic water and hydrophilic heads $\left(\mathrm{RH}^{ \pm}\right)$of $\alpha$-amino acids with the introduction of dipolar aprotic DMF in water. Glycine being smaller in size it will be strongly associated with water through hydrogen bonding. Therefore, glycine may be more destabilized (i.e., more inflection) (Table-3) during its transfer from protic water to dipolar aprotic $\mathrm{N}, \mathrm{N}$-dimethyl formamide. Here it is important to note that from $0-20 \mathrm{~mol} \%$ of DMF $\Delta \mathrm{G}_{\mathrm{t}, \mathrm{ch}}^{0}(\mathrm{i})$ values are higher for glycine than DL-alanine. After $20 \mathrm{~mol} \%$ of DMF $\Delta \mathrm{G}_{\mathrm{t}, \mathrm{ch}}^{0}(\mathrm{i})$ values are progressively negative for glycine than DL-alanine. Therefore the order of stability with respect to chemical contribution of solute-solvent interaction upto about 0-20 mol \% of N,N-dimethyl formamide is as DL-Ala. > Gly and after that stability is reverse i.e., Gly $>$ DL-Ala.

Water is a protic solvent, while N,N-dimethyl formamide is an aprotic in nature. Thereby anionic part $\left(\mathrm{COO}^{-}\right)$of these amino acids can be more solvated in water than N,N-dimethyl formamide due to acid-base interaction. Furthermore, in respect of $\mathrm{H}$-bonding capacity water is more potential than $\mathrm{N}, \mathrm{N}$-dimethyl formamide. So it is expected that amino acids will be less solvated initially with increased concentration of $\mathrm{N}, \mathrm{N}$-dimethyl formamide in water-DMF mixtures.

Here it is to be noted that with the increased concentration of DMF the $\Delta \mathrm{G}_{\mathrm{t}, \mathrm{ch}}^{0}(\mathrm{i})$ values of these amino acids decreases sharply. This decrement is higher for glycine than DL-alanine. Here DMF due to its dipolar aprotic character it can enhance its aproticity through the formation of intermolecular dimeric, (DMF) $)_{2}$ aprotic form (Fig. A) induced by the solutes (i.e. amino acids). Therefore DMF may stabilize the $\alpha$-amino acids through dispersion interaction overcoming destabilization due to poorer H-bonding and hydrophilic hydration with increased mole \% of DMF in aqueous-DMF system. 
<smiles>C[N+](C)(C)C=CC(=O)[O-]</smiles>

(A)

It should be noted that DMF $(0.498 \AA)^{26}$ is more polarisable than water $(0.274 \AA)^{26}$. Therefore DMF, here undergo stronger soft-soft and dispersion interactions with amino acids. But here the $\alpha$-amino acids also induce the hydrophilic hydration and hydrophobic hydration, which to be decreased with the increased DMF concentration.

The $\mathrm{NH}_{3}{ }^{+}$of the zwitterionic $\alpha$-amino acids $\left(\mathrm{RH}^{ \pm}\right)$takes part in acid-base interaction with DMF. Since DMF has larger basicity than water towards cation as their 'cation-N-centre' type acid-base interactions, the aqueous-DMF mixtures with its increased concentration of DMF acquire co-solvent induced $^{18,31}$ greater basicity. Therefore DMF can take part in acid-base interaction with $\mathrm{NH}_{3}{ }^{+}$moiety of $\alpha$-amino acids and imparts greater stability for the amino acids in comparison to water. On the other hand with increasing addition of DMF in water, the co-solvent induced acidity of DMF-water mixtures will be decreased to a much greater extent. Therefore $\mathrm{COO}^{-}$ of amino acids $\left(\mathrm{RH}^{ \pm}\right)$experiences instability to greater extent with the increased concentration of DMF in aqueous DMF system. Thus in the context of co-solvent induced acid-base interactions extra stability are not gained by the $\alpha$-amino acids with increased concentration of DMF. It is to be noted here also that the stability of $\alpha$-amino acids due to hydrophilic interaction exerted by the water molecules in its higher concentration will be more decreased due to co-solvent induced hydrophilicity with the increased concentration of DMF. In case of hydrophobic hydration it will also be reduced.

Therefore, the lightest $\alpha$-amino acid i.e., glycine having smaller size (5.64 $\AA$ ) will be more stabilized with increased concentration of DMF by acid-base type and relative hydrophilic interaction than others due to greater charge density on it. Here the effect due to size dependent dispersion interaction may play lesser important role than acid-base type and hydrophilic interactions. Therefore with the increased concentration of DMF, $\Delta \mathrm{G}_{\mathrm{t}, \mathrm{ch}}^{0}(\mathrm{i})$ values become more negative for glycine than DL-alanine. In case of DL-alanine the dispersion interaction is more significant than acid-base type interaction and hydrophilic interaction. The stability order of glycine and DLalanine at higher concentration of DMF will support Fig. 2 considering the combined effects of dispersion, acid-base and hydrophilic interactions.

Thus the chemical contribution $\Delta \mathrm{G}_{\mathrm{t}, \mathrm{ch}}^{0}(\mathrm{i})$ of transfer free energies, of these homologous $\alpha$-amino acids are guided by the composite effects of increased dispersion interaction, basicity and decreased acidity, hydrogen bonding effects, hydrophilic interaction and hydrophobic hydration of water and N,N-dimethyl formamide mixtures as compared to that of reference solvent (water).

Amino acids induced solvent-solvent interactions in terms of transfer entropy: Fig. 3 represent the variation of

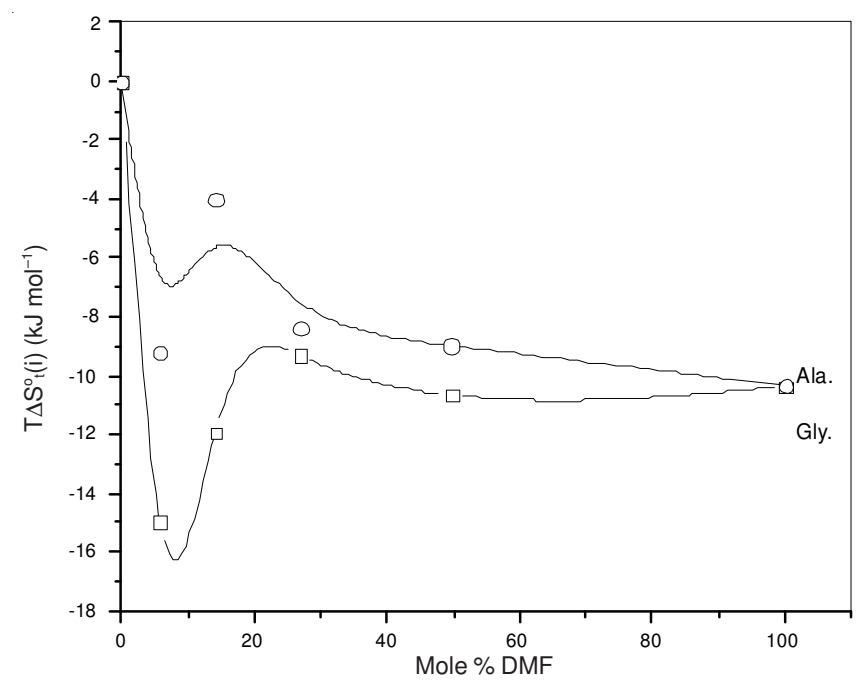

Fig. 3. Variation of $\mathrm{T} \Delta \mathrm{S}_{\mathrm{t}}{ }^{0}(\mathrm{i})$ of glycine, DL-alanine with mole $\% \mathrm{DMF}$ in aqueous mixture of DMF at $298.15 \mathrm{~K}$

$\mathrm{T} \Delta \mathrm{S}_{\mathrm{t}}^{0}(\mathrm{i})$ values of these homologous $\alpha$-amino acids with mole $\%$ DMF in DMF-water mixed solvent system. Here the roller coaster behaviour is shown by the amino acids. Now like, $\Delta \mathrm{G}_{\mathrm{t}}^{0}(\mathrm{i}), \mathrm{T} \Delta \mathrm{S}_{\mathrm{t}}^{0}(\mathrm{i})$ mainly composed of $\mathrm{T} \Delta \mathrm{S}_{\mathrm{t}, \mathrm{cav}}^{0}(\mathrm{i}), \mathrm{T} \Delta \mathrm{S}_{\mathrm{t}, \mathrm{d}-\mathrm{(i}}^{0}(\mathrm{~S})$ and $\mathrm{T} \Delta \mathrm{S}_{\mathrm{t}, \mathrm{ch}}^{0}(\mathrm{i})\left(\mathrm{T} \Delta \mathrm{S}_{\mathrm{t}, \mathrm{d}-\mathrm{id}}^{0}(\mathrm{i})\right.$ i.e., dipole induced dipole interaction is ignored here). $T \Delta S_{t, c a v}^{0}(i), T \Delta S_{t, d-d}^{0}(i)$ values are presented in Table-3.

At $c a .8 \mathrm{~mol} \%$ of DMF values shows a broad minima and then it sharply increases upto about $20 \mathrm{~mol} \%$ of DMF concentration. Above $20-100 \mathrm{~mol} \%$ of DMF, T $\Delta \mathrm{S}_{\mathrm{t}}^{0}(\mathrm{i})$ values show almost similar trends for both the amino acids. These observations indicate that water molecules adopt 3-D structure due to its extensive intermolecular hydrogen bonding (Fig. B) at lower concentration of DMF and then the hydrogen bonds are broken due to the introduction of dipolar aprotic co-solvent DMF. In higher concentration of this co-solvent molecules dimerisation may occur to form six member ring (Fig. A) to increase dispersion interactions but other types of solventsolvent interactions may decrease which represent such type of observed results.

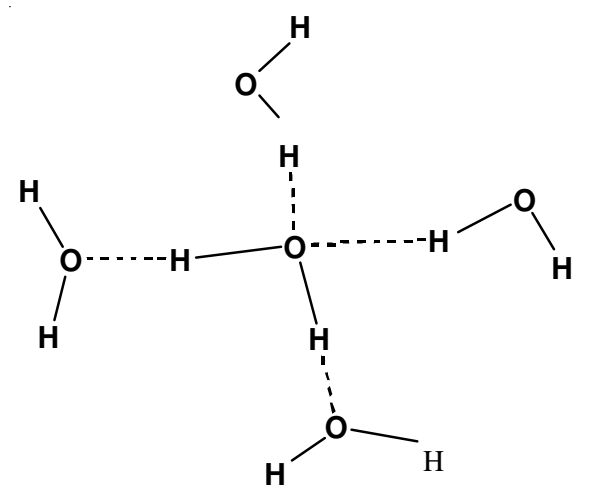

(B)

$\mathrm{T} \Delta \mathrm{S}_{\mathrm{t}, \mathrm{ch}}^{0}(\mathrm{i})$ is obtained after subtraction of $\mathrm{T} \Delta \mathrm{S}_{\mathrm{t}, \mathrm{cav}}^{0}(\mathrm{i})$ and $\mathrm{T} \Delta \mathrm{S}_{\mathrm{t}, \mathrm{d}-\mathrm{d}}^{0}(\mathrm{i})$ from $\mathrm{T} \Delta \mathrm{S}_{\mathrm{t}}^{0}(\mathrm{i})$. Fig. 4 represents the variation of $\mathrm{T} \Delta \mathrm{S}_{\mathrm{t}, \mathrm{ch}}^{0}(\mathrm{i})$ for the $\alpha$-amino acids glycine and DL-alanine with increased DMF concentration in aqua-DMF mixture at $25^{\circ} \mathrm{C}$. With increase of DMF concentration from $\mathrm{T} \Delta \mathrm{S}_{\mathrm{t}, \mathrm{ch}}^{0}(\mathrm{i})$ values 


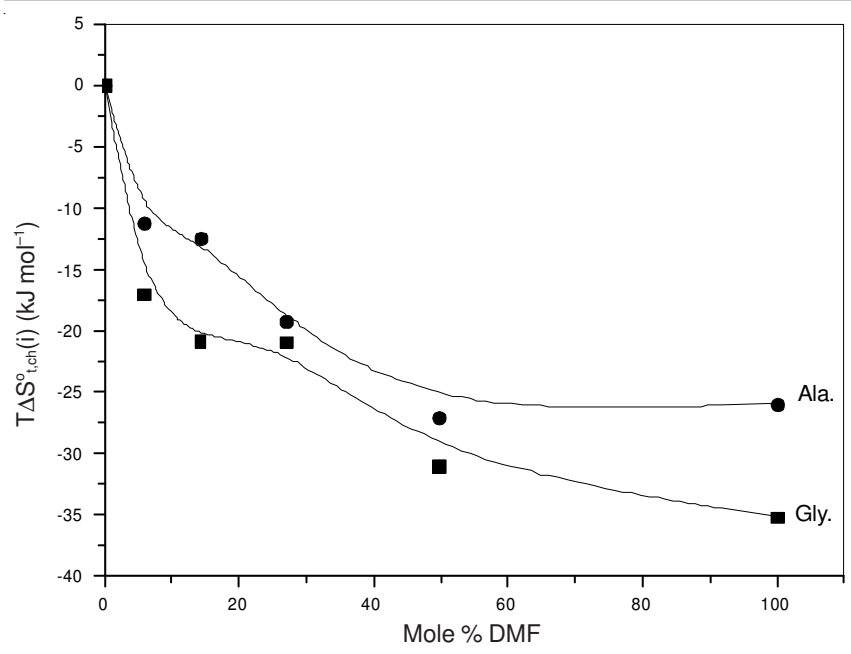

Fig. 4. Variation of $\mathrm{T} \Delta \mathrm{S}_{\mathrm{t}, \mathrm{ch}}^{0}(\mathrm{i})$ of glycine and DL-alanine with mole \% DMF of aqueous mixture of DMF at $298.15 \mathrm{~K}$

are decreased more or less regularly. This indicate that the $\alpha$ amino acids induce dipolar aprotic N,N-dimethylformamide to be dimerized (Fig. A) which is responsible for more dispersion interaction. But here the $\alpha$-amino acids also induce the hydrophilic hydration and hydrophobic hydration to be decreased with the increased DMF concentration. Comparatively for larger $\alpha$-amino acid i.e., DL-alanine, the more dis-orderness than glycine is observed due to weak response towards hydrophilic and hydrophobic interactions.

But the solute (amino acids) induced dispersion interaction among large size DMF molecules being the predominant factor over others the overall decrement of $\mathrm{T} \Delta \mathrm{S}_{\mathrm{t}, \mathrm{ch}}^{0}(\mathrm{i})$ values occur throughout the higher concentration of DMF in this aqua-DMF mixed solvent system.

\section{Conclusion}

It may be concluded that due to chemical interaction the $\alpha$-amino acids will be stabilized in DMF having dipolar aprotic character. The zwitterionic $\alpha$-amino acids induce to adopt 3 -D-structuredness of water at water rich concentration in aqua-DMF solvent system.

\section{ACKNOWLEDGEMENTS}

The authors gratefully acknowledged the support of the DST-SAP, UGC, Govt. of India and Department of Chemistry, Visva-Bharati University and Kalyani University for financial assistance and computational facilities.

\section{REFERENCES}

1. S. Lapamje, Physico-chemical Aspects of Proteins Denaturation. Wiley Intercience, New York, p. 241 (1978).

2. F. Köseoglu, E. Kiliç and A. Dogan, Anal. Biochem., 277, 243 (2002).

3. T.S. Banipal, G. Singh and B.S. Lark, J. Solut. Chem., 30, 657 (2001).

4. M.N. Islam and R.K. Wadi, Phys. Chem. Liq., 39, 77 (2001).

5. P. Das, S. Chatterjee and I. Basu Mallick, J. Chin. Chem. Soc., 51, 1 (2004).

6. T. Ooi and M. Oobatake, J. Biochem., 103, 114 (1988).

7. G.I. Makhatadze and P.L. Privalov, J. Mol. Biol., 232, 639 (1993).

8. C.B. Anfinsen and H.A. Seheraga, Adv. Protein Chem., 29, 205 (1978).

9. C. Jolicoeur and J. Boileau, Can. J. Chem., 56, 2707 (1978).

10. Y. Nozaki and C. Tanford, J. Biol. Chem.., 238, 4074 (1963).

11. M. Abu-Hamdiyyah and A. Shehabuddin, J. Chem. Eng. Data, 27, 74 (1982).

12. S. Roy, K. Mahali and B.K. Dolui, Biochemistry-An Indian J., 3, 63 (2009).

13. S. Roy, K. Mahali and B.K. Dolui, Biochemistry-An Indian J., 3, 71 (2010).

14. K. Gekko and S.N. Timasheff, Biochemistry, 20, 4677 (1981).

15. S. Ganguly and K.K. Kundu, J. Phys. Chem., 97, 10862 (1993).

16. S. Roy, K. Mahali, S. Akhtar and B.K. Dolui, Asian. J. Chem., 25, 6661 (2013).

17. S. Chatterjee and I. Basumallick, J. Chin. Chem. Soc., 54, 1 (2007).

18. K. Mahali, S. Roy and B.K. Dolui, J. Biophys. Chem., 2, 185 (2011).

19. J. Datta and K.K. Kundu, J. Phys. Chem., 86, 4055 (1982).

20. J. Datta and K.K. Kundu, Can. J. Chem., 61, 62 (1983).

21. H. Talukdar, S.P. Rudra and K.K. Kundu, Can. J. Chem.., 66, 461 (1988).

22. K. Majumder (Sengupta) and S.C. Lahiri, J. Indian Chem. Soc., 74, 382 (1997).

23. S.C. Dutta and S.C. Lahiri, J. Indian Chem. Soc., 72, 315 (1995).

24. R. Sinha, S.K. Bhattacharya and K.K. Kundu, J. Mol. Liq., 122, 95 (2005).

25. R.A. Pierotti, J. Phys. Chem., 67, 840 (1963).

26. Y. Marcus, Ion Solvation. John Willy \& Sons, New York (1985).

27. J.I. Kim, A. Cocal, H. Born and E.A. Comma, Z. Phys. Chem. Neue Folge., 110, 209 (1978).

28. R. Sinha and K.K. Kundu, J. Mol. Liq., 111, 151 (2004).

29. N.E. Hill, W.E. Baughan, A.H. Price and M. Davics, Dielectric Properties and Moleculer Behaviour, Van Nostrand Reinhold Comp. London (1969).

30. B.K. Dolui, S.K. Bhattacharya and K.K. Kundu, Indian J. Chem., 45A, 2607 (2006).

31. P.K. Guha and K.K. Kundu, Can. J. Chem., 63, 798 (1985). 